\title{
Neonatal convulsions associated with primary disturbance of calcium, phosphorus, and magnesium metabolism
}

\author{
F. COCKBURN, J. K. BROWN, N. R. BELTON, and J. O. FORFAR \\ From the Department of Child Life and Health, University of Edinburgh, Simpson Memorial Maternity Pavilion, and \\ Royal Hospital for Sick Children, Edinburgh
}

Cockburn, F., Brown, J. K., Belton, N. R., and Forfar, J. O. (1973). Archives of Disease in Childhood, 48, 99 . Neonatal convulsions associated with primary disturbance of calcium, phosphorus, and magnesium metabolism. The biochemical relations in 75 newborn infants suffering from convulsions considered to be due to a primary disturbance of mineral metabolism have been studied.

Hypocalcaemia was present in $92 \%$ of cases, hypomagnesaemia in $53 \%$, and hyperphosphataemia in $64 \%$. In nearly $80 \%$ of cases combinations of biochemical disturbance were present, the commonest being hypocalcaemia/hypomagnesaemia/ hyperphosphataemia; hypocalcaemia/hyperphosphataemia; and hypocalcaemia/ hypomagnesaemia. Isolated hypocalcaemia occurred in $19 \%$ of cases but isolated hypomagnesaemia in only $3 \%$.

Changes in the concentrations of calcium, phosphorus, and magnesium in the CSF mirrored those in the blood but were less pronounced.

Osmolality in blood and CSF was the same in normal and in convulsing infants and there was no difference between these two groups of infants. There are wide differences in the osmolality of breast milk on one hand and most evaporated milk feeds on the other.

In terms of associated neurological findings, infants suffering from convulsions due to a primary disturbance of mineral metabolism show a distinctive but not wholly exclusive clinical pattern.

In therapy magnesium appears to have an important role in rectifying not only hypomagnesaemia but also hypocalcaemia.

The prognosis in convulsions due to primary disturbance of mineral metabolism is good.

Neonatal convulsions may result from a variety of causes including primary disturbance of mineral metabolism (Schwartz, 1965; McInerney and Schubert, 1969; Freeman, 1970; Rose and Lombroso, 1970).

\section{Material and methods}

The present study concerns 75 consecutive newborn infants seen over a two-year period with convulsions considered to be due primarily to disordered calcium phosphorus, or magnesium metabolism. Observed over the same period, and excluded from this report, were 60 infants with convulsions considered to be due primarily to brain damage in whom mineral metabolism

Received 13 June 1972. was also frequently disturbed. The basis on which these two groups were differentiated has already been described (Brown, Cockburn, and Forfar, 1972).

All the convulsing infants were fed on an evaporated milk formula. In order to obtain comparable normal biochemical values a group of 41 breast-fed infants were also studied on the 5 th, 6 th, and 7 th days of life and a group of 60 artificially fed infants (fed the same evaporated milk formula as the convulsing infants) throughout the first week of life. The convulsing infants were examined at the time of the convulsion and several times thereafter until the biochemical results were normal.

The mean gestational age of the convulsing infants based on expected date of delivery was $39 \cdot 7$ weeks (range 34-43): there were 5 preterm infants (less than 37 weeks). The mean birthweight was $3359 \mathrm{~g}$ (range 
2013-4564), 6 infants weighing less than $2500 \mathrm{~g}$. There were 46 males to 29 females, a ratio of $3: 2$. 51 of the infants were delivered by spontaneous vertex delivery; 24 by forceps or lower segment caesarean section; none by breech delivery.

All 75 infants were examined neurologically on the basis of a modified form of the scheme of examination suggested by Prechtl and Beintema (1964), and gestational age assessed. Whenever possible neurological examination was carried out at the time of, or immediately after, the fit and also later during an interictal phase. Follow-up neurological examination was carried out at 4 months and again at 1 year.

Biochemical estimations on convulsing infants were carried out on plasma from lithium heparinized venous blood obtained usually from the femoral vein as soon after a convulsion as possible and before the institution of therapy. In control cases heparinized capillary blood plasma obtained by heel prick was examined $2 \frac{1}{2}$ to 3 hours after a feed. Blood plasma was analysed for calcium and magnesium by atomic absorption spectrophotometry (Unicam Atomic Absorption Method Instruction Sheets $\mathrm{Ca} 1 \mathrm{Mg}$ 1) for phosphate by the phosphomolybdate method (Fiske and Subbarow, 1925), and for glucose by the glucose oxidase method (Huggett and Nixon, 1957). Osmolality was estimated by the freezing point depression method using an 'Advance' osmometer.

Breast milk and various evaporated milk formulae used for infant feeding were examined for calcium, magnesium, and phosphorus concentration and osmolality. Concentrations of calcium, magnesium, and phosphorus in CSF were estimated in 23 infants with convulsions and in 15 infants without convulsions but with pyrexia of unknown origin in whom lumbar puncture had been carried out as part of a routine infection screen and the CSF found to be normal.

\section{Biochemical results}

Blood. In Fig. 1 individual plasma calcium concentrations in the convulsing infants are plotted against the range of normal values for infants fed on evaporated milk (based on mean \pm 1 SD) and the individual values for normal breast fed infants. The infants with convulsions had significantly lower plasma calcium concentrations than breast and artificially fed infants without convulsions. Convulsing infants with calcium values in the normal range had subnormal magnesium concentrations. Plasma magnesium concentrations are plotted in a similar manner in Fig. 2. Though in some infants with convulsions plasma magnesium concentrations were normal, the majority were significantly below the concentrations found in non-convulsing infants who were breast fed and artificially fed. Plasma phosphorus concentrations (Fig. 3) were generally higher in convulsing infants than in those without convulsions who were

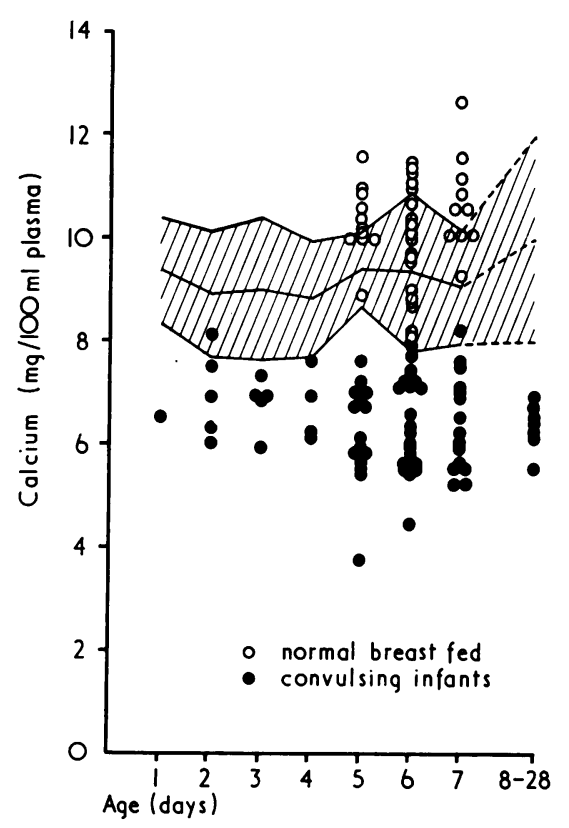

FIG. 1.-Plasma calcium concentrations in normal infants who were breast fed and convulsing infants who were fed evaporated milk, compared with range (mean $\pm 1 S D$ ) for normal evaporated milk-fed infants.

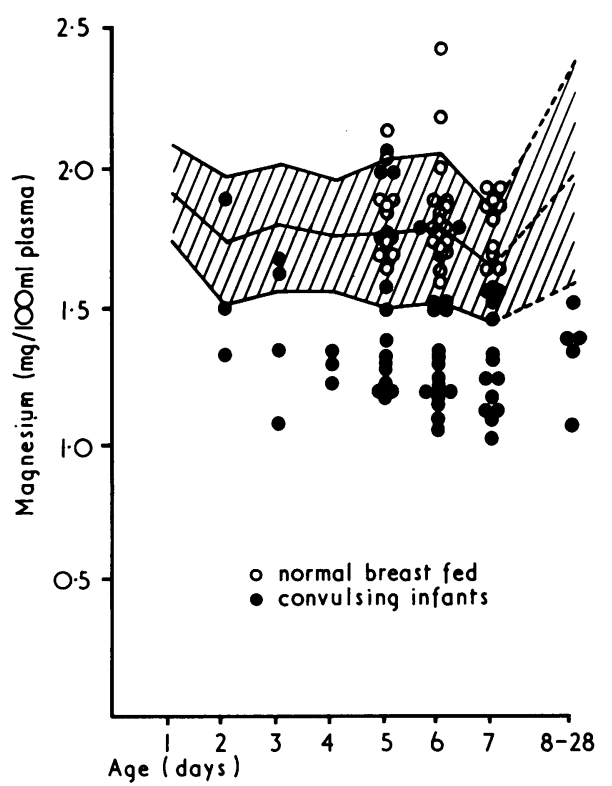

FIG. 2.-Plasma magnesium concentrations in normal infants who were breast fed and convulsing infants who were fed evaporated milk, compared with range (mean $\pm 1 S D$ ) for normal evaporated milk-fed infants. 


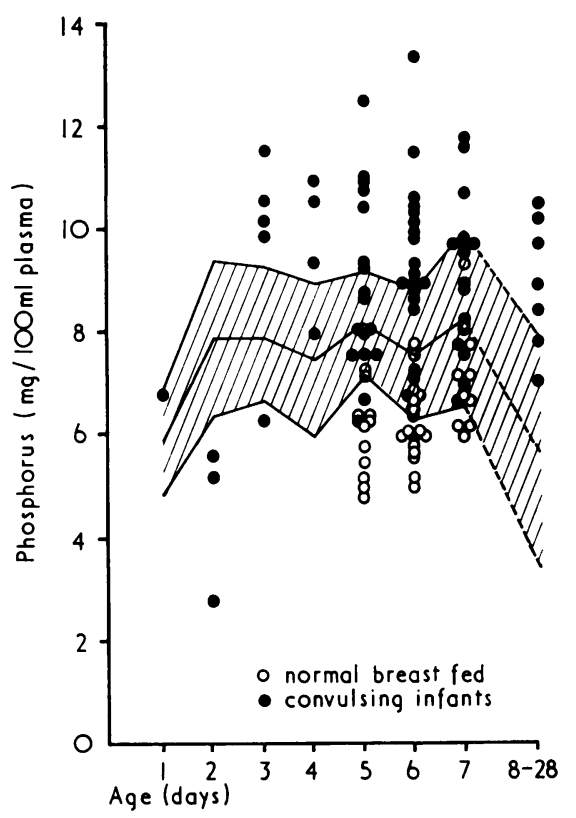

FIG. 3.-Plasma phosphorus concentrations in normal infants who were breast fed and convulsing infants who were fed evaporated milk, compared with range (mean \pm $1 S D)$ for normal evaporated milk-fed infants.

breast fed or artificially fed. In the 3 infants with low plasma phosphorus concentrations on the second day, the convulsions followed exchange transfusion (there was also hypocalcaemia).

The various combinations of calcium, magnesium, and phosphorus disturbance are shown in Table I

\section{TABLE I}

Calcium, magnesium, and phosphorus, patterns of disturbance in neonatal convulsions due to primary disturbance of mineral metabolism

\begin{tabular}{l|l|l|c|c}
\hline Calcium & Magnesium & Phosphorus & No. cases & $\%$ \\
\cline { 1 - 2 } Low & Low & High & 24 & 32 \\
Low & Normal & High & 20 & 27 \\
Low & Normal & Normal & 14 & 19 \\
Low & Low & Normal & 11 & 15 \\
Normal & Low & High & 3 & 4 \\
Normal & Low & Normal & 2 & 3 \\
Normal & Normal & High & 1 & 1 \\
\hline
\end{tabular}

Low $/$ high $=$ more than 2 SDs below/above the mean for normal breast-fed infants.

in which concentrations are designated high or low if they are outside a range derived from the mean \pm 2 SDs of normal breast-fed infants. Hypocalcalcaemia was associated with hyperphosphataemia in approximately $60 \%$ of convulsing cases and with hypomagnesaemia in approximately $50 \%$ of cases. Hypomagnesaemia without associated hypocalcaemia occurred in $7 \%$ of cases-as an isolated abnormality in less than half of these and associated with hyperphosphataemia in the remainder.

Correlation coefficients were calculated among calcium, magnesium, phosphorus, and glucose concentrations in the convulsing infants. The only significant correlation (positive) was between calcium and magnesium $(P=<0.01)$.

Mean values (and ranges) for plasma calcium, magnesium, and phosphorus concentrations over the period 5th, 6th, and 7th days of life, in breastfed normal infants, evaporated milk-fed normal infants, and evaporated milk-fed convulsing infants are analysed in Table II together with the plasma glucose concentrations. Concentrations of calcium, phosphorus, magnesium, and glucose in normal infants who were artificially fed were significantly different from concentrations in those who were breast fed; similarly, concentrations of calcium, phosphorus, magnesium, and glucose in convulsing infants were significantly different from concentrations in normal breast-fed infants; and concentrations of calcium, magnesium, and phosphorus, but not glucose, were significantly different in infants with convulsions from those without convulsions, fed on the same evaporated milk feeds.

Other factors such as plasma protein concentration and $p \mathrm{H}$ may influence ionization of calcium. Total plasma protein measured on the 6th day of life was not significantly different in artificially-fed infants $(6 \cdot 2 \pm 0 \cdot 3 \mathrm{~g} / 100 \mathrm{ml})$ compared with breastfed infants $(6.0 \pm 0.5 \mathrm{~g} / 100 \mathrm{ml})$. In capillary blood there was no significant difference in $p \mathrm{H}$ between those infants who were artificially fed $(7 \cdot 37 \pm 0 \cdot 04)$ and those who were breast fed $(7 \cdot 36 \pm 0 \cdot 02)$. Changes in plasma potassium concentration may also be associated with tetany. Plasma potassium was measured in 30 infants with convulsions and in only one case was it less than $3.5 \mathrm{mEq} / \mathrm{l}$. In $14 \%$ of convulsing infants serum sodium was greater than $150 \mathrm{mEq} / 1$. and in $20 \%$ less than $135 \mathrm{mEq} / 1$.

CSF. In the normal infants the mean calcium value in the CSF $(6 \cdot 6 \pm 1 \cdot 1 \mathrm{mg} / 100 \mathrm{ml})$ was lower than in plasma $(10 \cdot 1 \pm 1.8 \mathrm{mg} / 100 \mathrm{ml})$ partly due to the lower protein concentration in the former (ionizable calcium would probably be more comparable in plasma and CSF). In convulsing infants CSF calcium $(5 \cdot 9 \pm 1.9 \mathrm{mg} / 100 \mathrm{ml})$ was reduced as well as plasma calcium $(6 \cdot 2 \pm 1 \cdot 5 \mathrm{mg} / 100 \mathrm{ml})$, but not so markedly (Fig. 4). Infants with convulsions maintained the usual significant difference 
Mean values and ranges for plasma calcium, magnesium, and phosphorus concentrations in breast-fed normal infant.

\begin{tabular}{|c|c|c|c|c|}
\hline & \multicolumn{4}{|c|}{ Calcium } \\
\hline & No. & Range & Mean & SD \\
\hline $\begin{array}{l}\text { (A) Breast-fed control } \\
\text { (B) Evaporated cow's milk-fed control } \\
\text { (C) Evaporated cow's milk-fed infants with convulsions }\end{array}$ & $\begin{array}{l}40 \\
72 \\
54\end{array}$ & $\begin{array}{l}8 \cdot 1-12 \cdot 7 \\
7 \cdot 2-12 \cdot 0 \\
3 \cdot 7-7 \cdot 9\end{array}$ & $\begin{array}{r}10 \cdot 2 \\
9 \cdot 3 \\
6 \cdot 3\end{array}$ & $\begin{array}{l}1 \cdot 0 \\
1 \cdot 2 \\
0 \cdot 9\end{array}$ \\
\hline $\begin{array}{l}\text { (A) } v(B) \\
\text { (A) } v(C) \\
\text { (B) } v(C)\end{array}$ & \multicolumn{4}{|c|}{$\begin{array}{l}P<0.001 \\
P<0.001 \\
P<0.001\end{array}$} \\
\hline
\end{tabular}

between plasma and CSF calcium concentrations but this difference was less due to the greater reduction of calcium in plasma.

In the normal infants mean magnesium concentration in the CSF $(2 \cdot 7 \pm 0.5 \mathrm{mg} / 100 \mathrm{ml})$ was higher than in plasma $(1.9 \pm 0.7 \mathrm{mg} / 100 \mathrm{ml})$. Both CSF magnesium $(2 \cdot 3 \pm 0 \cdot 6 \mathrm{mg} / 100 \mathrm{ml})$ and plasma magnesium $(1.4 \pm 0.5 \mathrm{mg} / 100 \mathrm{ml})$ were reduced in convulsing infants (Fig. 5). The difference between concentrations of magnesium in plasma and CSF seen in the normal infant was therefore maintained also in infants with convulsions.

In the normal infants mean phosphorus concentration in CSF $(1 \cdot 9 \pm 1.2 \mathrm{mg} / 100 \mathrm{ml})$ was significantly lower than in plasma $(7 \cdot 5 \pm 2 \cdot 5 \mathrm{mg} / 100 \mathrm{ml})$. In convulsing infants the mean concentration of phosphorus in CSF $(1.9 \pm 0.8 \mathrm{mg} / 100 \mathrm{ml})$ was not significantly different from normal in contradistinction to the higher plasma concentration $(8 \cdot 7 \pm 1 \cdot 6 \mathrm{mg} / 100 \mathrm{ml})$. The difference between CSF and plasma phosphorus concentrations seen in the normal was thus maintained in convulsing infants.

Osmolality-blood and CSF. Osmolality

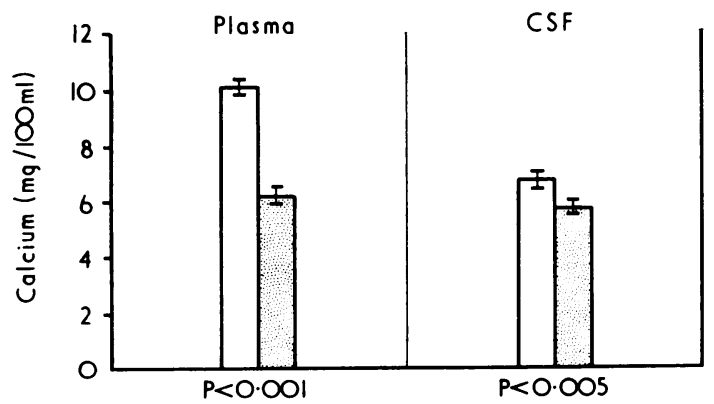

Fig. 4.-Mean plasma and CSF calcium concentrations in 15 normal (clear columns) and 23 convulsing (shaded columns) infants ( $\pm 1 S E)$.
( $\mathrm{mOsm} / \mathrm{kg}$ water) in body fluids is normally very constant. In 19 newborn infants with normal CSF, matched blood and CSF specimens taken simultaneously were available. There was no significant difference between mean plasma $(284 \pm$ $17 \mathrm{mOsm})$ and CSF $(283 \pm 14 \mathrm{mOsm})$ osmolality. Blood and CSF were available from a group of convulsing infants, not always simultaneously. 24 of these infants at the time of the fit had a mean plasma osmolality of $286 \pm 24$ mOsm. CSF osmolality in 22 infants with convulsions was $282 \pm$ 17 mOsm. There was thus no difference between blood and CSF osmolality in infants with or without convulsions.

Composition and osmolality of various milks. Sample calcium, magnesium, and phosphate concentrations and osmolality in various milks used are shown in Table III. Much higher values for calcium and phosphorus were found in modified (evaporated) cow's milk compared with human milk, and added dextrose produced a markedly hyperosmolar feed. These analyses were repeated at different times of the year in view of the seasonal incidence of convulsions, but no significant differences were found.

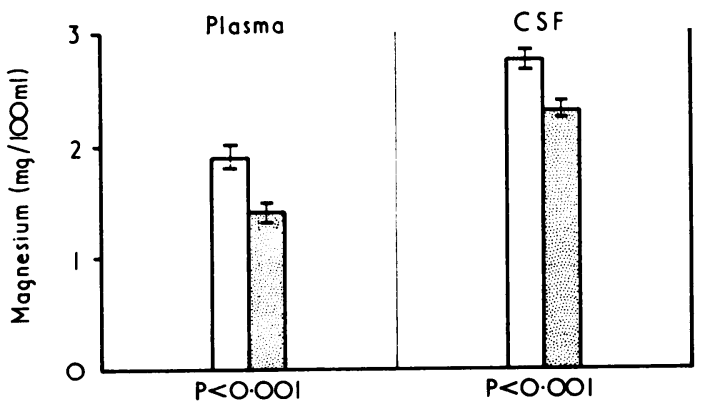

FIG. 5.-Mean plasma and CSF magnesium concentrations in 15 normal (clear columns) and 23 convulsing (shaded columns) infants ( 1 SE) 
evaporated milk-fed normal infants, and evaporated milk-fed convulsing infants over the 5th, 6th, and 7th days of life

\begin{tabular}{|c|c|c|c|c|c|c|c|c|c|c|c|}
\hline No. & Range & Mean & SD & No. & Range & Mean & SD & No. & Range & Mean & SD \\
\hline \multicolumn{4}{|c|}{$\begin{array}{l}\mathrm{P}<0.001 \\
\mathrm{P}<0.001 \\
\mathrm{P}<0.001\end{array}$} & \multicolumn{4}{|c|}{$\begin{array}{l}P<0.05 \\
P<0.001 \\
P<0.001\end{array}$} & \multicolumn{4}{|c|}{$\begin{array}{l}P<0.005 \\
P<0.001 \\
P<0.23\end{array}$} \\
\hline
\end{tabular}

TABLE III

Calcium, magnesium, and phosphorus content in milks

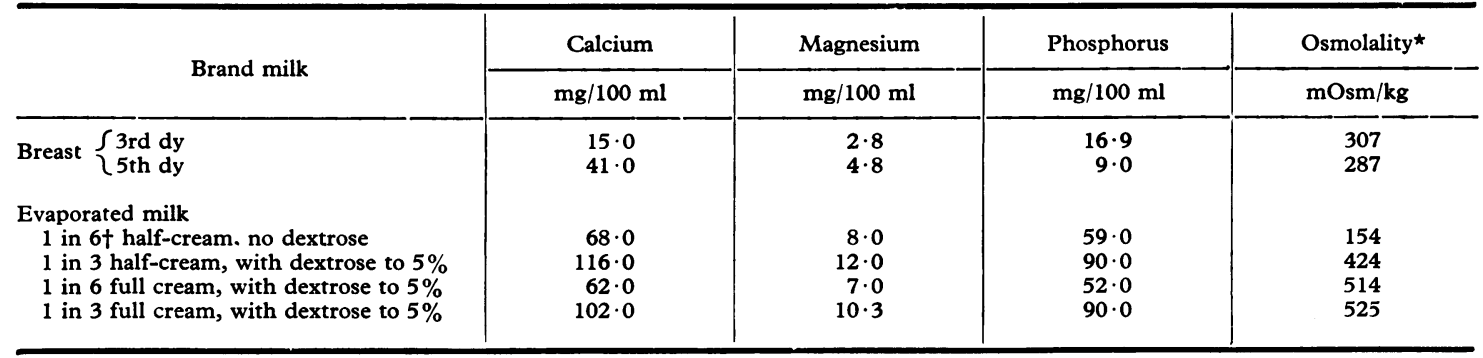

^No correction is made for varying lipid content.

+1 part milk to 5 parts water.

Maternal plasma values. Maternal plasma (venous samples taken in the puerperium) was analysed for calcium, magnesium, phosphorus, and alkaline phosphatase in 26 mothers of infants with prolonged convulsive episodes (Table IV). The values were not significantly different from those found in a group of $\mathbf{3 0}$ normal mothers (at delivery) whose infants did not have convulsions. None of the mothers in the convulsions group suffered from hyperparathyroidism or a malabsorptive state; only 4 suffered from severe pre-eclamptic toxaemia, a condition likely to impair placental transfer of calcium (Khattab and Forfar, 1971). During

\section{TABLE IV}

Values for calcium, magnesium, phosphorus, and alkaline phosphatase in 26 mothers of convulsing infants (samples taken during puerperium)

\begin{tabular}{lc|c|c|c}
\hline & No. & Mean & \multicolumn{1}{|c|}{ Range } & SD \\
\cline { 5 - 5 } Calcium (mg/100 ml) & 26 & $9 \cdot 6$ & $7 \cdot 9-12 \cdot 7$ & $1 \cdot 0$ \\
Magnesium (mg/100 ml) & 21 & $1 \cdot 9$ & $1 \cdot 4-2 \cdot 3$ & $0 \cdot 27$ \\
Phosphorus (mg/100 ml) & 25 & $3 \cdot 5$ & $2 \cdot 3-5 \cdot 2$ & $0 \cdot 8$ \\
Alkaline phosphatase & 13 & $19 \cdot 0$ & $7 \cdot 0-33 \cdot 0$ & $6 \cdot 2$ \\
$\quad$ (King-Armstrong units) & & & & \\
\hline
\end{tabular}

pregnancy, calcium concentrations in serum are lower than normal (Khattab and Forfar, 1970).

\section{Clinical findings}

Convulsion. The peak incidence of the first convulsion was on the sixth day of life. Convulsions were rare in the first 48 hours or after the tenth day. They were cortical in type. A typical convulsion consisted of rhythmic, focal, myoclonic jerking at a rate of 1 or 3 per second. In the same patient the site could vary exhibiting a multifocal patternright-sided in one episode, left in another, face more than leg, or some other distribution. Discharges from two separate foci could cause separate patterns of fit to occur simultaneously. Spread by a Jacksonian march could occur and the fits become generalized, the infant often becoming distressed, deteriorating in feeding behaviour, and showing cyanosis: hypocalcaemia and hypomagnesaemia per se did not cause cyanosis which only occurred when the infant was having a coincidental convulsion. In the 75 infants, observed fits (85) were focal in 31, multifocal in 34, and generalized in 20. True tonic and clonic grand mal fits were not seen.

There was a seasonal variation with convulsions occurring most commonly in April and May. 
Neurological examination. All the infants scored commensurate with chronological age on gestational age assessment based on cutaneous and general characteristics, and neurological assessment. The latter was considered valid as no infant was hypotonic (hypotonia causes an apparent reduction in gestational age score whereas hypertonia does not). Frequent neurological findings are given in Table V.

\section{TABLE V}

Neurological signs in 73 infants in whom primary hypocalcaemic/hypomagnesaemic convulsions occurred

\begin{tabular}{l|c} 
Abnormal EEG & $45(60 \%)$ \\
$\quad$ Epileptic EEG & $29(39 \%)$ \\
Increased deep reflexes & $39(52 \%)$ \\
Increased muscle tone & $27(36 \%)$ \\
$\quad$ Marked & $11(15 \%)$ \\
Moderate & $16(21 \%)$ \\
Jitteriness & $27(36 \%)$ \\
Clonus & $25(33 \%)$ \\
Hyperalertness & $20(26 \%)$ \\
Transient hemisyndrome & $12(16 \%)$ \\
Splaying of skull sutures & $12(16 \%)$ \\
'Sunsetting' of the eyes & $7(9 \%)$ \\
High pitched cry & $3(4 \%)$ \\
\end{tabular}

The infants were either in a normal state of alertness during the interictal period $(74 \%)$ or were hyperalert (26\%). None was apathetic. Hyperalartness could remain during a convulsion and in some instances an infant continued to feed while convulsing provided the fit was focal and not generalized.

Many of these babies were classically 'jittery'. This was marked in $35 \%$ though minor degrees were frequent. In the 'jittery' baby hand tremor is faster than convulsive movements and should not be confused with them. On the other hand, tetanic hamstring clonus shown by a spontaneous oscillation at the knee is slower than hand tremor and can easily be confused with a convulsive movement. If, however, the knee is passively flexed and the muscle relaxed, spontaneous oscillations stop, whereas in a convulsion the movements of the leg continue despite this passive flexion. Hamstring clonus can be produced by suddenly extending the infant's knees.

Tetany-shown by very brisk tendon reflexes; ankle, jaw, and hamstring clonus, and tremor of the arms-was considered to be present in $52 \%$ of cases but in a quarter of these was judged to be no more severe than may be seen in a normal very hungry hyperalert infant. Chvostek's sign was positive in less than $50 \%$ of infants with hypocalcaemia but a 'main d'accoucheur' as shown in older illustrations (Thomson, 1925) was not seen.
In $36 \%$ of cases there was an increase in extensor muscle tone (the normal hyperalert infant may show an increase in basic flexor tone). In severe cases $(15 \%)$, the pattern of extensor hypertonus could be that of decerebrate rigidity or full opisthotonus. In milder cases $(21 \%)$ the infant lay in the supine position with legs extended, ankles dorsiflexed, and toes extended in the spontaneous Babinski pattern (Fig. 6): neck retraction or even full opisthotonus

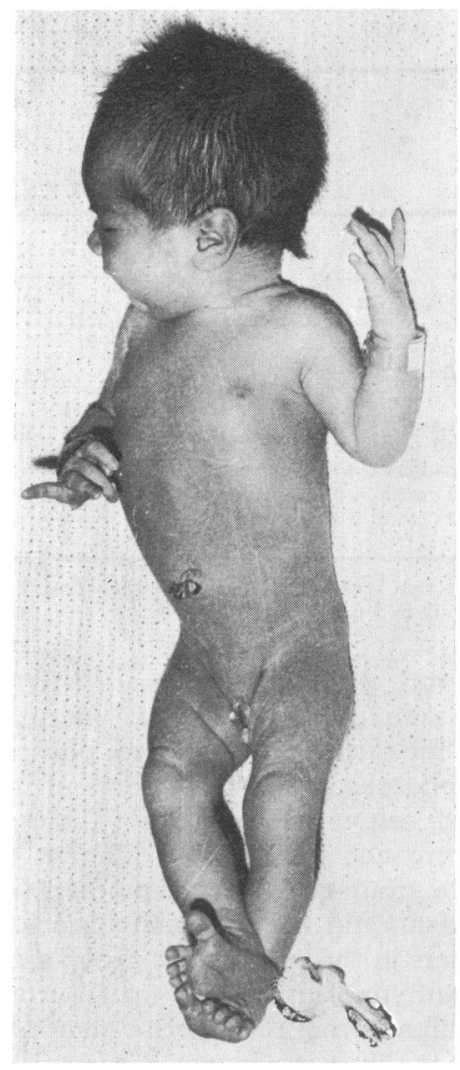

FIG. 6.-Posture in hypocalcaemia.

could occur. In the prone position the infant could lie with legs extended, instead of flexed under the abdomen, and excessively good head control with retraction of the head and shoulders and occasionally a lifting of the head and shoulders off the bed could occur, the infant assuming a posture at a week not usually seen until the age of 4 months (Fig. 7). On suspension in the prone position the infant could feel like a log with the trunk and legs horizontal instead of flexed at the hips with knees at right angles. Extensor reflexes, not usually obvious in the early days of life, such 


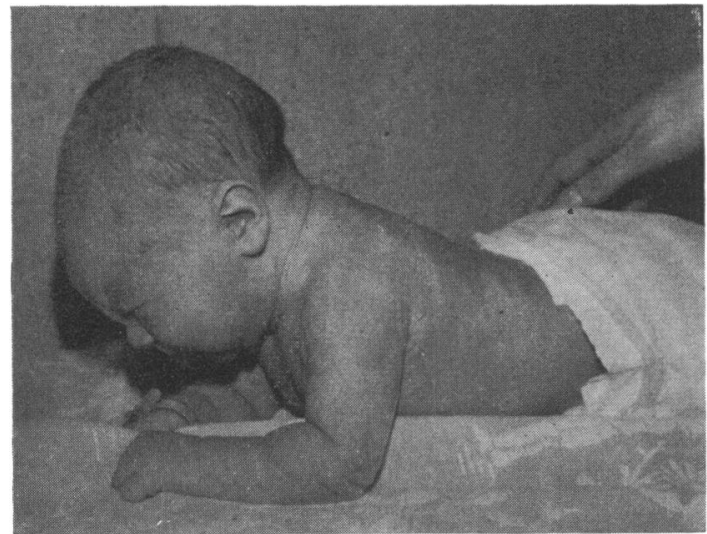

FIG. 7.-Apparent advanced motor achievement (at 7 days) in hypocalcaemia.

as the asymmetric tonic neck reflex, the crossed extensor reflex, the incurvation reflex, and the Perez reflex were usually brisk and uninhibited and could be obligatory. The deep reflexes, particularly the knee jerks, were judged to be exaggerated in $52 \%$ of cases and clonus was present in $33 \%$ of cases. Generalized hypotonia was not seen in any case.

A transient hemisyndrome was found in $16 \%$ of cases, usually on the same side as the convulsion and lasting only for a few hours after a fit (neonatal Todd's paralysis). On the affected side there could be hypotonia with loss of recoil, reduction of spontaneous movement, no resistance to the scarf test, and an easy heel-to-ear approximation with an exaggerated popliteal angle. This was the only type of hypotonia seen. Asymmetry of phasic reflexes or of the asymmetric tonic neck reflex was also seen as a hemisyndrome.

Of the infants, $9 \%$ had marked 'sunsetting' of the eyes and $16 \%$ splaying of the sutures up to $1 \mathrm{~cm}$. These signs were not necessarily associated with each other. Isolated 'sunsetting' might be due to a direct midbrain effect of hypocalcaemia. Cerebral oedema associated with hypocalcaemia might cause splaying of the sutures.

An electroencephalographic tracing taken during the fit or in the peri-ictal period was considered to be abnormal in $60 \%$ of cases and frankly epileptic in $39 \%$. Conspicuously absent neurological signs were apathy, hypotonia, absence of the Moro reflex, increased spontaneous movement, persistent hemisyndrome, ophthalmoplegia, and bulbar palsy. A high pitched cry was recorded in only $4 \%$ of infants. Tube feeding and the need for active resuscitation at birth were infrequent antecedents.
In $31 \%$ of infants there were no neurological abnormalities.

Treatment. In the initial stages of the investigation the importance of hypomagnesaemia in maintaining hypocalcaemia, and therefore convulsions, was not fully realized. A standard regimen of 5 to $10 \mathrm{ml}$ of a $10 \%$ solution of calcium gluconate was given by mouth before each feed. Several infants continued to convulse and were given calcium gluconate intravenously $(2-10 \mathrm{ml}$ of a $10 \%$ solution) under electrocardiographic and electroencephalographic control. Intravenous calcium gluconate usually caused bradycardia but could also cause inversion of $P$ waves on the ECG, taken as an early sign of cardiotoxicity. Though the plasma concentration rose with intravenous therapy this was short lived and a convulsion could recur within an hour or two and convulsions continued sometimes up to several weeks.

Later, treatment with magnesium sulphate $50 \%$ solution $0.2 \mathrm{ml} / \mathrm{kg}$ i.m. per day) was routine in all hypomagnesaemic convulsing infants. With this it became unnecessary to administer calcium intravenously. No case continued to convulse after the plasma magnesium had returned to normal.

The effect on plasma calcium of giving magnesium without added calcium can be seen in Fig. 8 .

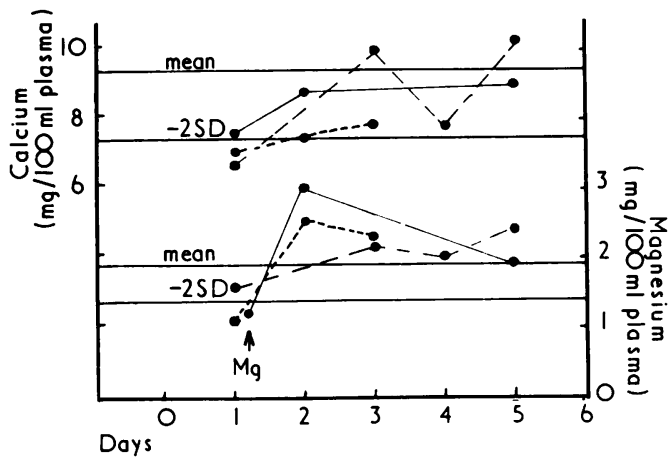

FIG. 8.-Effect of magnesium on serum calcium concentrations in neonatal hypocalcaemia (3 cases) (arrow indicates intramuscular administration of magnesium). 'Day 1' is the day of the first convulsion.

Plasma calcium as well as magnesium concentrations rose. Fig. 9 illustrates two cases in which serum calcium rose with oral therapy and one in which it did not: in all three convulsions continued and magnesium concentrations fell. On giving magnesium the serum calcium as well as magnesium concentrations rose.

Calcium alone was given to 21 infants and com- 


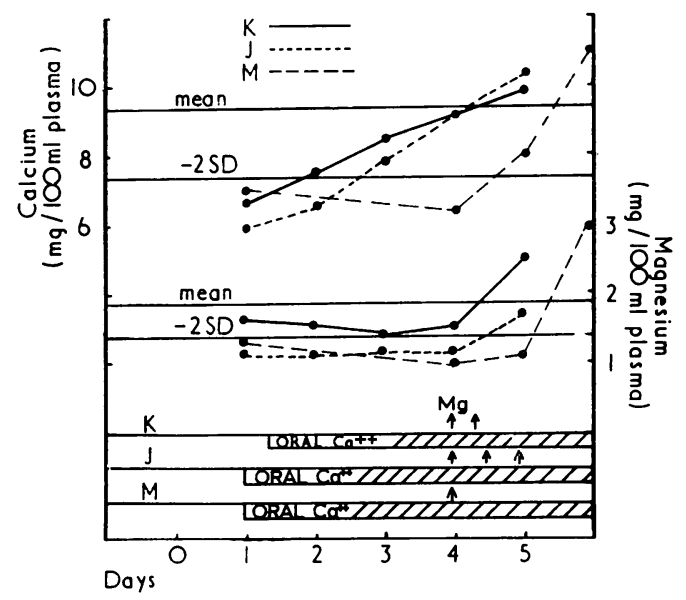

FIG. 9.- Effect of magnesium on serum calcium concentrations in 3 cases where oral calcium had failed to relieve hypocalcaemia (arrows indicate intramuscular administration of magnesium). 'Day 1' is the day of the first convulsion.

bined with other therapy in 36 so that $57(77 \%)$ received calcium gluconate. The total amount of calcium gluconate given before the fits stopped or the plasma concentration returned to normal varied between 70 and $500 \mathrm{ml}$ or 0.6 to $4.1 \mathrm{~g}$ calcium. 33 infants received magnesium sulphate, 9 as the only form of treatment. 5 infants did not receive calcium or magnesium though the concentrations of these were abnormal, and their convulsions ceased spontaneously. 17 infants were given phenobarbitone early in the series or later while awaiting biochemical results.

Magnesium is not without danger in the newborn period; overdosage can cause a curare-like neuromuscular blocking action. Only two doses were allowed to each infant before re-estimating plasma magnesium. In 9 infants, after treatment, clinical hypermagnesaemia (without plasma magnesium more than 2 SDs above the mean in 8) occurred with symmetrical bilateral hypotonia, poor recoil in the arms which lay extended at the infant's side, no resistance to the scarf test, hypotonia in the legs with easy approximation of heel to ear, and an exaggerated popliteal angle. These signs were transient and lasted less than 24 hours. They were not severe enough to require intravenous calcium which, by re-establishing the ratio of $\mathrm{Ca}^{++}$to $\mathrm{Mg}^{++}$ on which normal neuromuscular transmission depends, would have been expected to reverse the condition.
Follow-up studies. 71 infants were seen at 4 months and 65 at 1 year. 60 infants $(85 \%)$ were considered normal at follow-up, 8 ( $11 \%$ ) were slow in reaching certain milestones or retained certain primitive reflexes, 1 was thought to be normal at 4 months but to have a mild degree of ataxia at 1 year, 1 showed extensor dystonia at 1 year, and 1 mild spasticity in the muscles of the left calf at 1 year. In those who were slow in reaching milestones or retained primitive reflexes none was considered to come within the category of mental subnormality and the clinical impression was that their intellectual state was in keeping with the parents' intelligence. None of the affected infants had a significant degree of handicap.

\section{Discussion}

In the 2-year period over which this study was carried out the proportion of neonatal convulsions due to primary disturbance of mineral metabolism was $55 \%$. In recent reports hypocalcaemia and hypomagnesaemia have been recorded as responsible for 20 to $34 \%$ of neonatal convulsions (Keen, 1969; McInerney and Schubert, 1969; Rose and Lombroso, 1970). Others, less specifically, have reported a high incidence of hypocalcaemic neonatal convulsions (Baum, Cooper, and Davies, 1968; Pugh, 1968; Eades, 1968). Earlier analyses of neonatal convulsions in this country (Burke, 1954; Craig, 1960; Harris and Tizard, 1960) reported hypocalcaemia as an aetiological factor in less than $1 \%$ of convulsions.

Thirty-five years ago, Bakwin (1937) showed that the administration of a solution of inorganic phosphorus to newborn infants resulted in a fall in serum calcium within 2 hours. While the concentrations of all the main mineral elementscalcium, phosphorus, and magnesium-are higher in cow's milk than in human milk, the order of change is not proportionate. The phosphorus/ calcium ratio in the former is $0.8 / 1$ (compared with $0 \cdot 2 / 1$ in human milk) and the phosphorus/ magnesium ratio $7 \cdot 5 / 1$ (compared with $1 \cdot 9 / 1$ ) (Table III). The hypocalcaemic effect of the disproportionately high phosphorus content of cow's milk may be mediated through transitory hypoparathyroidism in the infant (Fanconi and Prader, 1967), calcium or vitamin $D$ deficiency in the mother (Watney et al., 1971), vitamin D administration to the infant (Gittleman, Pinkus, and Schmerztler, 1964), or lack of vitamin D in the infant (Barr and Forfar, 1969). Hypomagnesaemia may also result from the disproportionate phosphorus load of cow's milk (Anast, 1964; Coussons, 1969) and factors which may further mediate hypomagnesaemia 
are magnesium deficiency in the mother, a transitory functional hypoparathyroidism (Davis, Harvey, and $\mathrm{Yu}, 1965$ ) impaired absorption (Paunier et al., 1965; Salet et al., 1966), and target unresponsiveness (Seelig, 1971).

Several reports on neonatal hypocalcaemia that responded to magnesium but not to calcium have appeared (Paunier et al., 1965; Davis et al., 1965; Salet et al., 1966). In conditions in which minimum calcium and magnesium requirements are met, the greater the calcium intake the less magnesium retained (Seelig, 1971). In dogs, acute intravenous loading with calcium increases renal excretion of magnesium (Wallach and Carter, 1961). Thus, the administration of calcium to an infant with hypocalcaemia and hypomagnesaemia may aggravate the hypomagnesaemia and maintain the convulsive state. On the other hand an increased magnesium intake where minimum mineral requirements are met results in increased calcium retention (Seelig, 1971). Further, infusion of magnesium into adult patients with hypocalcaemia and hypomagnesaemia results in an increase in ionized calcium (as well as magnesium) (Zimmet, Breidahl, and Nayler, 1968). It has been suggested that magnesium deficiency interferes with the release of calcium from bone and that correction of the deficiency is necessary to increase the movement of calcium into plasma (Heaton and Fourman, 1965). Thus, in contradistinction to calcium administration, the administration of magnesium to infants with hypocalcaemia and hypomagnesaemia is likely to correct both conditions. These observations provide a limited rationale for the effect of magnesium alone both in raising calcium and in curing convulsions and for the periodic therapeutic failure of calcium.

Magnesium is predominantly an intracellular ion and in newborn infants who have suffered from birth asphyxia the plasma magnesium rises (Engel and Elin, 1970). In the convulsions with a primary disturbance of mineral metabolism reported here the CSF magnesium concentration fell, reflecting the fall in the plasma magnesium; likewise the CSF calcium fell, but the degree of fall was less marked than in plasma. These findings suggest that the changes in CSF calcium and magnesium which occur in hypocalcaemic hypomagnesaemic convulsions are secondary and due to blood changes rather than to any specific changes within the central nervous system.

While hypocalcaemic and hypomagnesaemic infants who convulsed frequently showed a clinical pattern compounded of hypertonicity, jitteriness, increased muscle response to stimulation, increased tendon reflexes, a hyperalert state between fits, and transient hemisyndrome, these signs are not always present, nor are they specific for primary hypocalcaemia/hypomagnesaemia. They may also occur in brain damaged infants probably due to the secondary disturbances of mineral metabolism which accompany brain damage (Brown et al., 1972). However, the combination of these signs in an artificially fed infant who develops convulsions between the fourth and tenth day and who appears normally alert and responsive between fits makes a primary disturbance of mineral metabolism a likely cause of the convulsion. A hyperalert state and transient hemisyndrome occur significantly more frequently in association with convulsions which are primarily metabolic than in those due to brain damage. On the other hand, certain neurological signs are almost invariably absent in primarily metabolic convulsions. These are marked apathy, hypotonia, absence of the Moro reflex, increased spontaneous movement, persistent hemisyndrome, ophthalmoplegia, and bulbar palsy. The presence of these signs, which are common in brain damage, almost excludes convulsions due primarily to hypocalcaemia or hypomagnesaemia. Thus the neurological picture in neonatal tetany is one of a cluster of certain signs in the absence of certain others.

As observed in this study, McInerney and Schubert (1969), Rose and Lombroso (1970), and Keen (1969) found the outcome satisfactory in the majority of neonatal convulsions due to primary hypocalcaemia and hypomagnesaemia.

We thank Miss Mary Taylor and the medical and nursing staff of the Special Care Unit, Simpson Memorial Maternity Pavilion, for a great deal of assistance, and Professor R. J. Kellar, Drs. G. D. Matthew, and W. D. A. Callam for permission to examine mothers under their care. Dr. Malcolm Mace undertook some of the biochemical estimations on control cases. The British Epilepsy Association made a grant towards the cost of this work and Mr. George Pollock facilitated and supported it.

\section{REFERENCES}

Anast, C. S. (1964). Serum magnesium levels in the newborn. Pediatrics, 33, 969.

Bakwin, H. (1937). Pathogenesis of tetany of the newborn. American fournal of Diseases of Children, 54, 1211.

Barr, D. G. D., and Forfar, J. O. (1969). Oral calcium-loading test in rickets and in neonatal tetany: effect of vitamin $D$. British Medical fournal, 3, 150.

Baum, D., Cooper, L., and Davies, P. A. (1968). Hypocalcaemic fits in neonates. Lancet, 1, 598.

Brown, J. K., Cockburn, F., and Forfar, J. O. (1972). Clinical and chemical correlates in convulsions of the newborn. Lancet, $1,135$.

Burke, J. B. (1954). The prognostic significance of neonatal convulsions. Archives of Disease in Childhood, 29, 342.

Coussons, H. (1969). Magnesium metabolism in infants and children. Postgraduate Medicine, 46, 135. 
Craig, W. S. (1960). Convulsive movements occurring in the first ten days of life. Archives of Disease in Childhood, $35,336$.

Davis, J. A., Harvey, D. R., and Yu, J. S. (1965). Neonatal fits associated with hypomagnesaemia. Archives of Disease in Childhood, 40, 286.

Eades, S. (1968). Hypocalcaemic fits in neonates. Lancet, 1, 644.

Engel, R. R., and Elin, R. J. (1970). Hypermagnesemia from birth asphyxia. Fournal of Pediatrics, 77, 631.

Fanconi, G., and Prader, A. (1967). Transient congenital idiopathic hypoparathyroidism. Helvetica Paediatrica Acta, 22, 342.

Fiske, C. H., and Subbarow, Y. (1925). The colorometric determination of phosphorus. fournal of Biological Chemistry, 66, 375.

Freeman, J. M. (1970). Neonatal seizures-diagnosis and management. Fournal of Pediatrics, 77, 701.

Gittleman, I. F., Pinkus, J. B., and Schmerztler, E. (1964). Interrelationship of calcium and magnesium in the mature neonate. American fournal of Diseases of Children, 107, 119.

Harris, R., and Tizard, J. P. M. (1960). The electroencephalogram in neonatal convulsions. Fournal of Pediatrics, 57, 501 .

Heaton, F. W., and Fourman, P. (1965). Magnesium deficiency and hypocalcaemia in intestinal malabsorption. Lancet, 2,50 .

Huggett, A. St. G., and Nixon, D. A. (1957). Enzymic determination of blood glucose (Abst.). Biochemical fournal, 66, 12P.

Keen, J. H. (1969). Significance of hypocalcaemia in neonatal convulsions. Archives of Disease in Childhood, 44, 356.

Khattab, A. K., and Forfar, J. O. (1970). Interrelationship of calcium, phosphorus and glucose levels in mother and newborn infant. Biology of the Neonate, 15, 26.

Khattab, A. K., and Forfar, J. O. (1971). The interrelationship between calcium, phosphorus and glucose levels in mother and infant in conditions commonly associated with 'placental insufficiency'. Biology of the Neonate, 18, 1 .

McInerney, T. K., and Schubert, W. K. (1969). Prognosis of neonatal seizures. American fournal of Diseases of Children, 117, 261.
Paunier, L., Radde, I. C., Koob, S. W. and Fraser, D. (1965). Primary hypomagnesemia with secondary hypocalcemia. (Abst.) Fournal of Pediatrics, 67, 945.

Prechtl, H. F. R., and Beintema, D. J. (1964). The Neurological Examination of the Full-Term Newborn Infant. Clinics in Developmental Medicine, No. 12. Heinemann, London.

Pugh, R. J. (1968). Hypocalcaemic fits in neonates. Lancet, 1, 644.

Rose, A. L., and Lombroso, C. T. (1970). A study of clinical, pathological, and electroencephalographic features in 137 full-term babies with a long-term follow-up. Pediatrics, 45, 404.

Salet, J., Polonovski, C., de Gouyon, F., Pean, G., Melekian, B., and Fournet, J. (1966). Tétanie hypocalcémique. Récidivante par hypomagnésemie congénitale. Archives Françaises de Pddiatrie, 23, 749.

Schwartz, J. F. (1965). Neonatal convulsions. Clinical Pediatrics, 4, 595 .

Seelig, M. (1971). Human requirements of magnesium factors that increase need. Proceedings of the 1st International Symposium on Magnesium Deficit in Human Pathology, p. 11 . Ed. by J. Durlach.

Thomson, J. (1925). Clinical Study and Treatment of Sick Children, 4th ed. Oliver and Boyd, Edinburgh and London.

Wallach, S., and Carter, A. C. (1961). Metabolic and renal effects of acute hypercalcemia in dogs. American fournal of Physiology, 200, 359.

Watney, P. J. M., Chance, G. W., Scott, P., and Thompson, J. M. (1971). Maternal factors in neonatal hypocalcaemia: a study in three ethnic groups. British Medical fournal, 2, 432.

Zimmet, P., Breidahl, H. D., and Nayler, W. G. (1968). Plasma ionized calcium in hypomagnesaemia. British Medical fournal, 1,622 .

Correspondence to Professor J. O. Forfar, Department of Child Life and Health, 17 Hatton Place, Edinburgh EH9 1UW. 